\title{
Ileocaecal intussusception due to submucosal lipoma in a pregnant woman
}

\author{
Willem-Maarten PF Bosman, Hugo TC Veger, Paul Ph Hedeman Joosten, Ewan \\ D Ritchie
}

Department of Surgery, Rijnland Ziekenhuis, Leiderdorp, Netherlands

Correspondence to Dr Willem-Maarten Bosman, w.bosman@rijnland.nl
CrossMark

\section{To cite: Bosman W-MPF,} Veger HTC, Hedeman Joosten PP, et al. BMJ Case Rep Published online: [please include Day Month Year] doi:10.1136/bcr-2013203110

\section{DESCRIPTION}

A 30-year-old woman was admitted to the emergency department with a 2-day history of colic pain in the left upper quadrant of the abdomen. She had been suffering from nausea and vomiting, which was attributed to her recent pregnancy ( \pm 8 weeks). Her medical history consisted of rheumatoid arthritis and unexplained abdominal pains which were paired with nausea and vomiting. Laboratory results were normal and showed only a positive pregnancy test. An ultrasound was performed by the gynaecologist and showed an empty womb, leading to the diagnosis of an ectopic pregnancy. During the diagnostic laparoscopy by the gynaecologist, there were no signs of an ectopic pregnancy, nor was another explanation for the abdominal pains found.

As the abdominal cramps remained, the next day an ultrasound of the abdomen was made by the radiologist, which showed an intussusception of the terminal ileum in the ascending colon (figure 1). The patient was referred to the general surgeon for emergency surgery. After a midline laparotomy, the ascending colon was mobilised and the diagnosis of

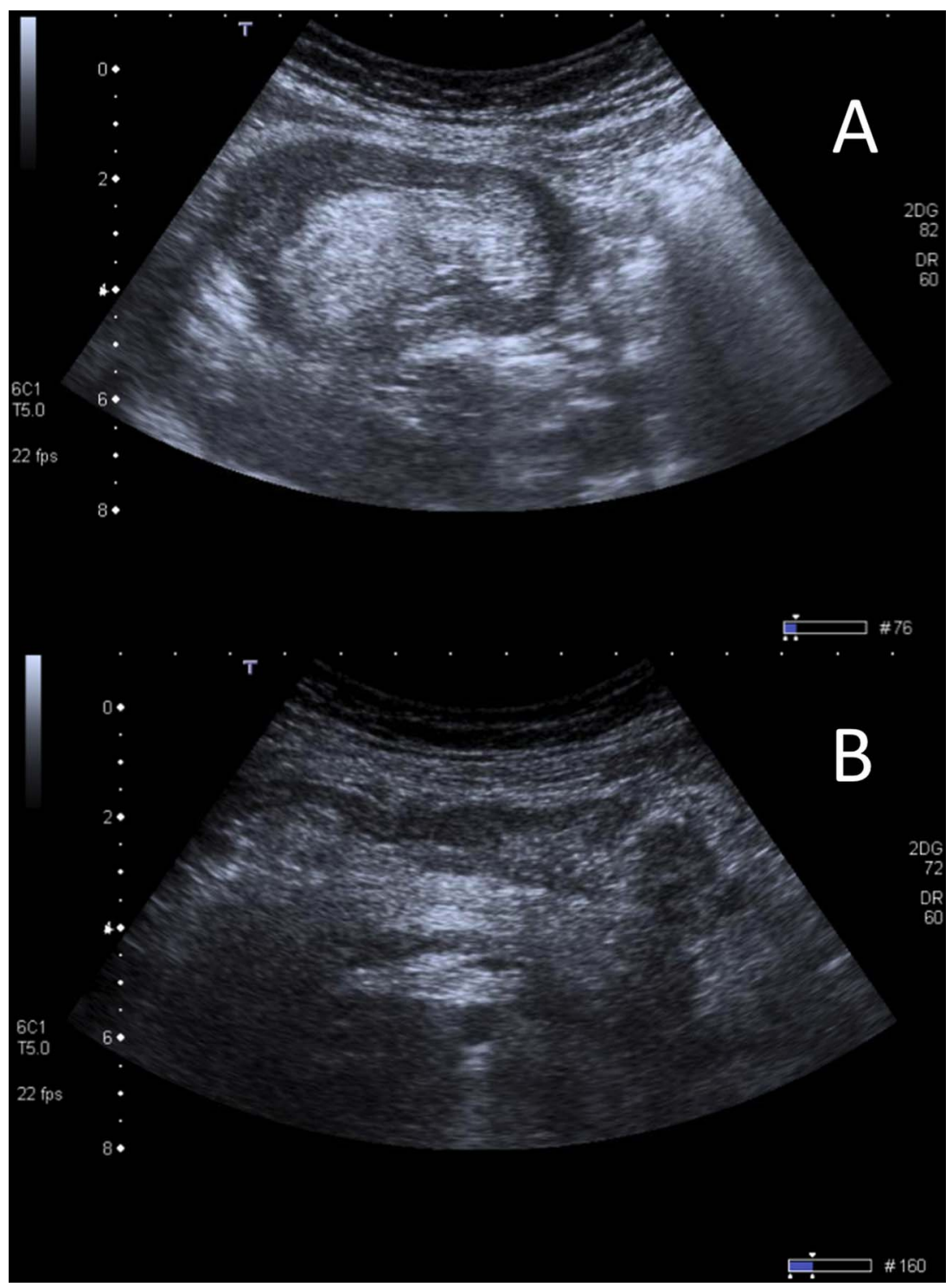

Figure 1 Ultrasound showing the intussusception of the terminal ileum and its mesenterial fat within the lumen of the ascending colon ((A) transversal view, (B) saggital view). 


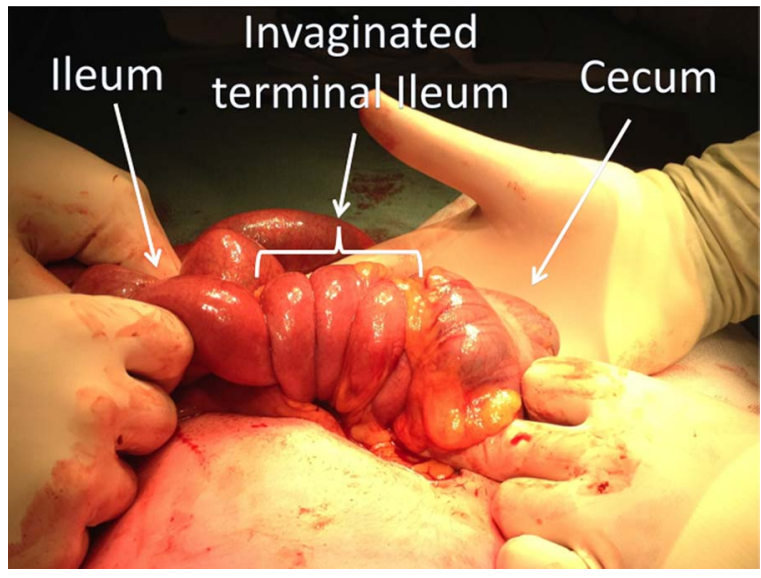

Figure 2 Midline laparotomy underlined the diagnosis of the ileocaecal intussusception. The terminal ileum was "telescoped" into the lumen of the caecum and the ascending colon.

ileocaecal intussusception was confirmed (figure 2). An ileocaecal resection with an end-side anastomosis of the ileum to transverse colon was performed.

The resected terminal ileum showed some submucosal tumours and the diagnosis of submucosal lipoma was confirmed by the pathologist after analysis (figure 3). Postoperative, a second ultrasound was made by the gynaecologist, showing an intact intrauterine pregnancy. The patient was able to return home 5 days after surgery. Unfortunately, she had to be readmitted, due to a superficial surgical wound infection. The infection was treated by removing the skin-sutures and opening the wound, leaving the abdominal fascia intact. Four weeks after the ileocaecal resection, a new ultrasound was carried out by the gynaecologist, in which an amnion was seen without signs of heart action. The missed abortion was removed by means of a vacuum curettage.

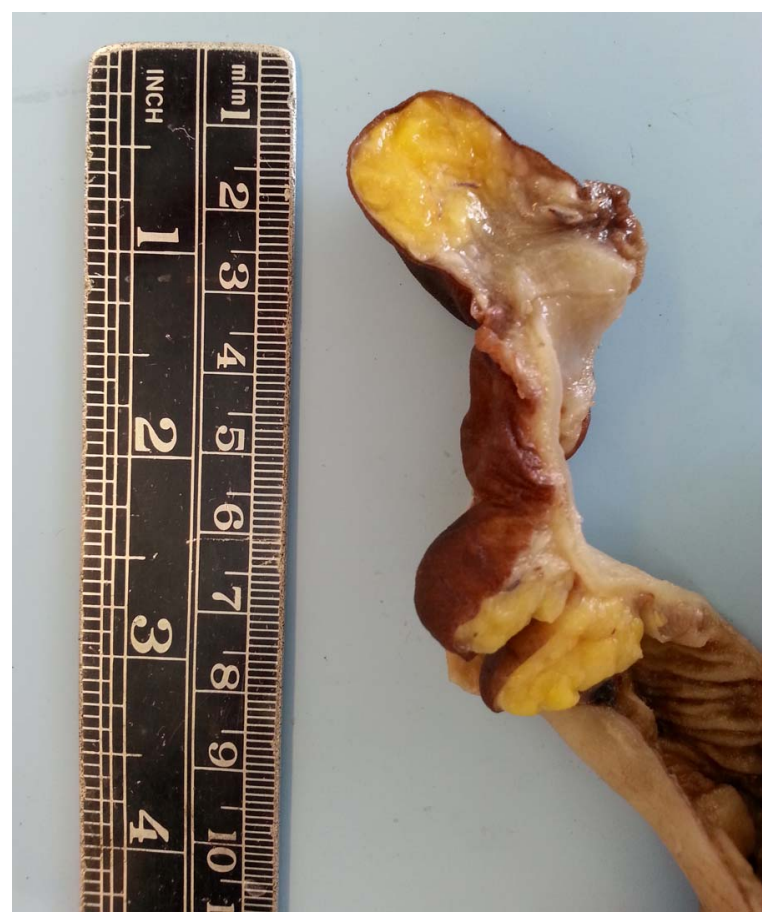

Figure 3 Macroscopic cross-sections showed several lipomatous tumours in the terminal ileum, located under the mucosa.
Ileal-caecal intussusception is a rare condition, often presenting with abdominal pain, nausea and vomiting. ${ }^{12}$ However, up to $20 \%$ of the intussusceptions may present without symptoms. ${ }^{2}$ Of all intussusceptions, only $5 \%$ take place in adults. ${ }^{3}$ Intussusception is defined as a prolapse of one segment of the intestines in to a distal segment. A tumour in the intestine forms a leading point after which the ileum telescopes in the colon through the caecal valve. The intussusception leads to venous and lymphatic congestion, resulting in oedema, when not treated, to intestinal ischaemia. ${ }^{3}$ Leading points may consist of benign tumours, malign neoplasms or enteric wall thickening due to inflammation. ${ }^{2}{ }^{3}$ Benign leading points for intussusception of the small bowel may consist of lipoma, Meckel's diverticulum, lymph nodes, adhesions or trauma, while malignant causes are often metastases or a rare primary small bowel tumour. About $20 \%$ of all cases are idiopathic. ${ }^{3}$

As symptoms may be aspecific, imaging modalities are essential for the definitive diagnosis. Ultrasound or CT-scan may show a so-called "doughnut sign" or a "target lesion", due to the several concentric rings of the abdominal layers of the intussuscepted bowel. ${ }^{1}$ This target sign can be seen in figure 1. Resection is the optimal treatment with adults in contrast to paediatric intussusception, in which closed reduction may be attempted.

In the current case, a submucosal lipoma was the leading point for the intussusception. Post mortem studies have shown submucosal lipoma in the gastrointestinal system in $0.2 \%$ of the population. Most lipomas are asymptomatic, until they become larger than $1-2 \mathrm{~cm}$. The most frequent symptoms of submucosal lipoma are haemorrhage, melaena, obstruction, constipation, cramps, diarrhoea and intussusception. ${ }^{3}$

The current case underlines the fact that physicians in the emergency department should remain suspicious of an intussusception as cause of abdominal tenderness, even when a pregnancy test is positive and signs of infection in blood results are absent. The patient was sent to the gynaecologist without additional imaging of the abdomen, leading to an unnecessary diagnostic laparoscopy and a delay of optimal treatment. It is very plausible, that the history of unexplained abdominal cramps with vomiting and nausea were due to existing partial intussusceptions of the lipoma.

\section{Learning points}

- A positive pregnancy test and the absence of infection blood results do not exclude a gastrointestinal explanation for abdominal pains.

- Be aware of the possibility of an ileocaecal intussusception by unexplained abdominal tenderness, especially if there is a history of abdominal cramps.

- Submucosal lipoma in the ileum may form as a leading point for ileocaecal intussusception.

Acknowledgements The authors would like to acknowledge the help of $W$ den Hartog MD, department of pathology and A C Breda Vriesman MD PhD, department of radiology for their help with the acquirement of the figures.

Contributors W-MB, HTCV, PPhHJ and EDR contributed equally to the clinical care of the patient and the writing of the manuscript.

Competing interests None.

Patient consent Obtained.

Provenance and peer review Not commissioned; externally peer reviewed. 


\section{REFERENCES}

1 Wani I, Muzafar I. Ileo-ileal intussusception in an adult by lipoma. World J Gastroenterol 2007;13:3641-4.

2 Lindor RA, Bellolio MF, Sadosty AT, et al. Adult intussusception: presentation, management, and outcomes of 148 patients. J Emerg Med 2012:43:1-6.
3 Oyen TL, Wolthuis AM, Tollens T, et al. Ileo-ileal intussusception secondary to a lipoma: a literature review. Acta Chir Belg 2007;107:60-3.

Copyright 2014 BMJ Publishing Group. All rights reserved. For permission to reuse any of this content visit http://group.bmj.com/group/rights-licensing/permissions.

BMJ Case Report Fellows may re-use this article for personal use and teaching without any further permission.

Become a Fellow of BMJ Case Reports today and you can:

- Submit as many cases as you like

- Enjoy fast sympathetic peer review and rapid publication of accepted articles

- Access all the published articles

- Re-use any of the published material for personal use and teaching without further permission

For information on Institutional Fellowships contact consortiasales@bmjgroup.com

Visit casereports.bmj.com for more articles like this and to become a Fellow 